Cytogenet Genome Res 1992;59:234-240

\title{
Contributors and Participants
}

Kweku K. Amfoh

Division of Biostatistics \& Epidemiology Howard University Cancer Center 2041 Georgia Avenue, N. W. Washington, D.C. 20060

John Blangero

Department of Genetics

Southwest Foundation for Biomedical Research

P.O. Box 28147

San Antonio, TX 78228

Chris Amos

Family Studies Section/EEB National Cancer Institute 6130 Executive Boulevard, \#439

Bethesda, MD 20892

Heike Blossey Department of Statistics University of Washington B313 Padelford, GN-22

Seattle, WA 98195

Stylianos E. Antonarakis

Department of Pediatrics

Johns Hopkins University School of Medicine

600 North Wolfe Street, CMSC 1004

Baltimore, MD 21205

Chris Aston

Western Psychiatric Institute and Clinic

University of Pittsburgh

3811 O'Hara Street

Pittsburgh, PA 15213

Joan Bailey-Wilson

Department of Biometry and Genetics

Louisiana State University Medical Center

1901 Perdido Street

New Orleans, LA 70112

Sherri J. Bale

National Institute of Arthritis, Musculoskeletal and Skin Diseases Building 6, Room 429

Bethesda, MD 20892

Terri H. Beaty

Department of Epidemiology

Johns Hopkins University School of Hygiene

615 N. Wolfe Street

Baltimore, MD 21205 
Wilma Bergman Department of Dermatology University Hospital Leiden Building 26, P.O. Box 9503 Leiden, 2300 RA THE NETHERLANDS

D. Timothy Bishop

Genetic Epidemiology Laboratory

Imperial Cancer Research Fund

3K Springfield House, Hyde Terrace

Leeds, LS2 9LU

ENGLAND

Michael Boehnke Department of Biostatistics University of Michigan 109 South Observatory Ann Arbor, MI 48109-2029

George E. Bonney Division of Biostatistics Howard University Cancer Center 2041 Georgia Avenue NW Washington, DC 20060

Ingrid Borecki

Division of Biostatistics

Washington University School of Medicine

660 S. Euclid Avenue, Box 8067

St. Louis, MO 63110

Lisa Cannon-Albright Genetic Epidemiology University of Utah Research Park 420 Chipeta

Way, Suite 180 Salt Lake City, UT 84108

Rita M. Cantor Neuropsychiatric Institute University of California, Los Angeles 760

Westwood Plaza Los Angeles, CA 90024

Rosalind Carter Center for Medical Genetics Blalock 1017, Johns Hopkins Hospital 600

North Wolfe Street Baltimore, MD 21205

Aravinda Chakravarti Department of Human Genetics University of Pittsburgh Crabtree Hall, Room A310 Pittsburgh, PA 15261

Gary A. Chase

Johns Hopkins

School of Public Health

624 North Broadway, Room 855

Baltimore, MD 21205

Elizabeth B. Claus Department of Epidemiology Yale University School of Medicine 60

College Street, P.O. Box 3333 New Haven, CT 06510

C. R. Colyer

Johns Hopkins University

School of Hygiene and Public Health

615 North Wolfe Street

Baltimore, MD 21205

P. Michael Conneally Department of Medical Genetics Indiana University Medical Center

975 W. Walnut Street Indianapolis, IN 46202

Josef Coresh

Department of Epidemiology

Johns Hopkins University School of Hygiene

615 North Wolfe Street

Baltimore, MD 21205

David R. Cox

Department of Psychiatry 
University of California, San Francisco

Box 0554

San Francisco, CA 94143

Gillian M. Cox

CRC Human Cancer Genetics Research Group

Department of Pathology

University of Cambridge

Tennis Court Road

Cambridge CB2 1QP

ENGLAND

Nancy Cox

Howard Hughes Medical Institute University of Chicago Hospitals 5841 South Maryland,

Box 391 Chicago, IL 60637

Gillian P. Crockford

Imperial Cancer Research Fund

3K Springfield House

Hyde Terrace

Leeds LS2 9LU

ENGLAND

Adrienne Cupples

Department of Epidemiology and Biostatistics

Boston University School of Public Health

80 East Concord Street

Boston, MA 02118

Florence Demenais Division of Biostatistics Howard University Cancer Center 2041 Georgia

Avenue NW Washington, DC 20060

T. E. Dobbins

Department of Biometry and Genetics

Louisiana State University Medical Center

1901 Perdido Street

New Orleans, LA 70112

J. A. Donald

School of Biological Sciences

Macquarie University

Marsfield, N.S.W. 2122

AUSTRALIA

D. L. Duffy

Queensland Institute for Medical Research

300 Herston Road

Brisbane, Queensland 4029

AUSTRALIA

Doug Easton

Section of Epidemiology

The Institute of Cancer Research

15 Cotswold Road, Block D

Belmont Surrey, SM2 5NG 


\section{ENGLAND}

Irene Eckstrand

National Institute of General Medical Sciences

$\mathrm{NIH}$

5333 Westbard Avenue, \#920

Bethesda, MD 20892

Janet D. Elashoff

Medical Genetics Birth-Defects Center

Cedars-Sinai Medical Center

8700 Beverly Blvd., ASB-3

Los Angeles, CA 90048

Catherine T. Falk

Lindsley F. Kimball Research Institute

New York Blood Center

310 East 67th Street

New York, NY 10021

Lindsay A. Farrer Department of Neurogenetics Boston University Medical Center 80 East

Concord Street Boston, MA 02118

Rune R. Frants

Department of Human Genetics

University Hospital Leiden

P.O. Box 9503

Leiden, 2300 RA

THE NETHERLANDS

236

Michael Frigge Department of Statistics The University of Chicago 5734 South University Avenue Chicago, IL 60637

Kathleen Gardiner

Roosevelt Institute for Cancer Research

1899 Gaylord Street

Denver, CO 80206

Luis Giuffra

Department of Human Genetics

Yale University School of Medicine

333 Cedar Street

New Haven, CT 06510

David Goldgar Genetic Epidemiology University of Utah Research Park 420 Chipeta Way, Suite 180 Salt Lake City, UT 84108

Lynn R. Goldin

Clinical Neurogenetics Branch

NIMH

9000 Rockville Pk., Building 10 3N218

Bethesda, MD 20892

Alisa M. Goldstein Family Studies Section/EEB National Cancer Institute Executive Plaza

North, \#439 Bethesda, MD 20892 
Darlene Goldstein Department of Statistics University of California, Berkeley Berkeley, CA 94720

Philip Green

Department of Genetics

Washington University School of Medicine

4566 Scott Avenue, Box 8031

St. Louis, MO 63110

David A. Greenberg Department oí Psychiatry Mount Sinai Medical Center 1 Gustav Levy

Place New York, NY 10029

Nelleke Gruis

Department of Human Genetics

University Hospital Leiden

Building 26, P.O. Box 9503

Leiden, 2300 RA

THE NETHERLANDS

Rudy Guerra Department of Statistics University of California, Berkeley Berkeley, CA 94720

Sun Wei Guo

Department of Biostatistics University of Washington Seattle, WA 98195

James F. Gusella Department of Neurogenetics Massachusetts General Hospital Fruit Street

Boston, MA 02114

Jonathan L. Haines Department of Neurogenetics Massachusetts General Hospital 13th

Street, Building 149, 6th floor Charlestown, MA 02114

Emily L. Harris

Department of Epidemiology

Johns Hopkins University School of Hygiene

615 North Wolfe Street

Baltimore, MD 21205

Carol Haynes Department of Neurology Duke University Medical Center Box 2900 Durham,

NC 27710

Nicholas Hayward

Human Genetics Laboratory

Queensland Institute for Medical Research

Bramston Terrace

Herston, Queensland 4006

AUSTRALIA

Susan E. Hodge

Department of Psychiatry

Columbia University School of Medicine

722 West 168th Street, Box 14

New York, NY 10032

Candace M. Kammerer

Department of Genetics

Southwest Foundation for Biomedical Research

P.O. Box 28147

San Antonio, TX 78228

Bronya Keats 
Department of Biometry and Genetics

Louisiana State University Medical Center

1901 Perdido Street

New Orleans, LA 70112

Richard F. Kefford Department of Medicine University of Sydney Westmead Hospital

Westmead, N.S.W. 2145 AUSTRALIA

Mary-Claire King School of Public Health University of California, Berkeley Berkeley, CA 94720

T. M. King

Johns Hopkins University

School of Hygiene and Public Health

615 North Wolfe Street

Baltimore, MD 21205

Augustine Kong Department of Statistics The University of Chicago 5734 South University

Avenue Chicago, IL 60637

Lyle W. Konigsberg Department of Anthropology University of Tennessee 252 South

Stadium Hall Knoxville, TN 37996

Amelia E. Laing Division of Biostatistics Howard University Cancer Center 2041 Georgia

Avenue NW Washington, DC 20060

Sharon Lawrence

Department of Community Medicine

University of Southampton

Tremona Road, South Block

Southampton, S09 4XY

ENGLAND

Thomas Lehner

New York State Psychiatric Institute

Columbia University

722 West 168th Street, Box 58

New York, NY 10032

Cathryn M. Lewis Genetic Epidemiology University of Utah Research Park 420 Chipeta

Way, Suite 180 Salt Lake City, UT 84108

R. A. Lewis

Pensylvania State University

University Park, PA 16802

Jean W. MacCluer

Department of Genetics

Southwest Foundation for Biomedical Researc

P.O. Box 28147

San Antonio, TX 78228

Allison M. Macdonald Genetics Section Institute of Psychiatry De Crespigny Park Denmark Hill London SE5 8AF ENGLAND

Nancy E. Maestri

Park 336

The Johns Hopkins Hospital

600 North Wolfe Street 
Baltimore, MD 21205

Nick G. Martin

Queensland Institute for Medical Research

300 Herston Road

Brisbane, Queensland 4029

AUSTRALIA

Maria Martinez

Clinical Neurogenetics Branch

NIMH

9000 Rockville Pk., Building 10 3N218

Bethesda, MD 20892

W. H. McCarthy Sydney Melanoma Unit Royal Prince Alfred Hospital Camperdown, N.S.W. 2050 AUSTRALIA

Barbara McKnight Department of Biostatistics University of Washington Seattle, WA 98195

M. S. McPeek Department of Statistics University of California, Berkeley Berkeley, CA 94720

Gerard J. te Meerman Vakgroep Medische Genetica Rijkuniversiteit Groningen Antonius

Deusinglaan 4 Groningen, 9713 AW THE NETHERLANDS

B. G. Mellen

Johns Hopkins University

School of Hygiene and Public Health

615 North Wolfe Street

Baltimore, MD 21205

238

Nancy Role Mendell

Department of Applied Mathematics and Statistics

SUNY - Stony Brook

Stony Brook, NY 11794

Laurence J. Meyer

4B454-Dermatology

University of Utah Medical Center

Salt Lake City, UT 84112

Deborah A. Meyers Center for Medical Genetics Blalock 1017, Johns Hopkins Hospital 600

North Wolfe Street Baltimore, MD 21205

Steven O. Moldin

Department of Psychiatry

The Jewish Hospital of St. Louis

216 South Kingshighway Boulevard

St. Louis, MO 63110

Newton E. Morton

Department of Community Medicine

University of Southampton

Tremona Road, South Block

Southampton, S09 4XY

ENGLAND

Mike Mullan 
Biochemistry Department

St. Mary's Hospital Medical School

Norfolk Place, Paddington

London, ENGLAND W21 PG

Charles Murigande

Department of Biostatistics and Epidemiology

Howard University Cancer Center

2041 Georgia Avenue NW

Washington, DC 20060

Richard H. Myers Department of Neurogenetics Boston University Medical Center 80 East

Concord Street Boston, MA 02118

Rosalind Neuman

Department of Psychiatry

Washington University School of Medicine

4940 Audubon Avenue, Box 8134

St. Louis, MO 63110

Jurg Ott

NYS Psychiatric Institute

Columbia University

722 West 168th Street, Box 58

New York, NY 10032

David Patterson Eleanor Roosevelt Institute 1899 Gaylord Street Denver, CO 80206

Margaret A. Pericak-Vance

Division of Neurology

Duke University Medical Center

Box 2900

Durham, NC 27710

Gloria M. Petersen Department of Epidemiology School of Hygiene and Public Health Johns Hopkins University Baltimore, MD 21205

Michael W. Piepkorn

Departments of Internal Medicine and Pathology

University of Utah Medical Center

Salt Lake City, UT 84112

Bruce Ponder Department of Pathology Cambridge University Tennis Court Road

Cambridge, CB2 1QP ENGLAND

Valerie L. Prenger

Department of Epidemiology

Johns Hopkins University School of Hygiene

615 N. Wolfe Street

Baltimore, MD 21205

Michael Province

Division of Biostatistics

Washington University School of Medicine

660 S. Euclid Avenue, Box 8067

St. Louis, MO 63110

D.C. Rao 
Division of Biostatistics

Washington University School of Medicine

660 S. Euclid Avenue, Box 8067

St. Louis, MO 63110

Julian E. Reefer Department of Human Genetics University of Pittsburgh Crabtree Hall, Room A310 Pittsburgh, PA 15261

John P. Rice

Department of Psychiatry

The Jewish Hospital of St. Louis

216 South Kingshighway Boulevard

St. Louis, MO 63110

239

Treva K. Rice

Division of Biostatistics

Washington University School of Medicine

660 S. Euclid Avenue, Box 8067

St. Louis, MO 63110

Neil Risch

Department of Epidemiology Yale University School of Medicine 60 College Street, P.O.

Box 3333 New Haven, CT 06510

M. B. Risman

Department of Dermatology University of Utah Medical Center Salt Lake City, UT 84112

J. K. Rivers

Sydney Melanoma Unit

Royal Prince Alfred Hospital

Camperdown, N.S.W. 2050

AUSTRALIA

Andre Rogatko

International Agency for Research on Cancer

150, cours Albert-Thomas

69372 Lyon Cedex 08,

FRANCE

Nan Rochberg

Department of Psychiatry

Washington University School of Medicine

4940 Audubon Avenue, Box 8134

Street Louis, MO 63110

Jeffrey Rogers

Department of Genetics

Southwest Foundation for Biomedical Research

P.O. Box 28147

San Antonio, TX78228

A. P. Round

85 West Street, Corfe Castle

Dorset, BH20 5HB

ENGLAND 
Judy A. Salmon Department of Medicine University of Sydney Westmead Hospital Westmead, N.S.W. 2145 AUSTRALIA

Lodewijk Sandkuijl Voorstraat 27A Delft, 2611 JK THE NETHERLANDS

H. M. Shaw

Sydney Melanoma Unit

Royal Prince Alfred Hospital

Camperdown, N.S.W. 2050

AUSTRALIA

Stephanie L. Sherman Division of Medical Genetics Emory University School of Medicine 2040 Ridgewood Dr. NE, Room 106 Atlanta, GA 30322

Mark Skolnick Genetic Epidemiology University of Utah Research Park 420 Chipeta Way, Suite 180 Salt Lake City, UT 84108

Susan A. Slaugenhaupt Department of Human Genetics University of Pittsburgh Crabtree Hall, Room A310 Pittsburgh, PA 15261

Terry Speed Department of Statistics University of California, Berkeley Berkeley, CA 94720

Marcy C. Speer

Division of Neurology

Duke University Medical Center

Research Park Building 1, \#116A, Box 2900

Durham, NC 27710

P. Michael Stewart Department of Statistics University of California @ Berkeley Berkeley, CA 94720

Peter Szolovits

MIT Laboratory for Computer Science 545 Technology Square Cambridge, MA 02139

Rudolph E. Tanzi Department of Neurogenetics Massachusetts General Hospital Fruit Street Boston, MA 02114

Joseph Terwilliger

NYS Psychiatric Institute

Columbia University

722 West 168th Street, Box 58

New York, NY 10032

240

Duncan C. Thomas

Department of Preventive Medicine

University of Southern California

1420 San Pablo Street

Los Angeles, CA 90033-9987

Elizabeth Thompson Department of Statistics University of Washington B313 Padelford, GN-22 Seattle, WA 98195

Camlin Tierney Department of Biostatistics University of Washington Seattle, WA 98195

Bradford Towne

Department of Pediatrics

Wright State Univ. School of Medicine

1005 Xenia Avenue

Yellow Springs, OH 45387 
James A. Trofatter Department of Neurogenetics Massachusetts General Hospital 13th Street, Building 149, 6th floor Charlestown, MA 02114

Margaret A. Tucker Family Studies Section/EEB National Cancer Institute Executive Plaza North, \#439 Bethesda, MD 20892

Paul Van Eerdewegh Department of Psychiatry The Jewish Hospital of St. Louis 216 South

Kingshighway Boulevard St. Louis, MO 63110

Veronica Vieland

Department of Psychiatry

Columbia University School of Medicine

722 West 168th Street, Box 14

New York, NY 10032

George P. Vogler

Division of Biostatistics

Washington University School of Medicine

660 S. Euclid Avenue, Box 8067

St. Louis, MO 63110

Andrew C. Warren

Department of Psychiatry

Johns Hopkins University School of Medicine

600 North Wolfe Street

Baltimore, MD 21205

Paul Watkins Lifecodes, Inc. 8717 Grovemont Circle Gaithersburg, MD 20877

Daniel E. Weeks

Department of Human Genetics

University of Pittsburgh, A300 Crabtree Hall

130 de Soto Street

Pittsburgh, PA 15261

Bruce S. Weir

Department of Statistics

North Carolina State University

Box 8203

Raleigh, NC 27695-8203

Lowell R. Weitkamp

Division of Genetics

University of Rochester Medical Center

601 Elmwood Avenue, Box 641

Rochester, NY 14642

Nancy Wexler

Departments of Neurology and Psychology

Columbia University School of Medicine

722 West 168th Street, Box 14

New York, NY 10032

Ellen M. Wijsman Department of Medical Genetics RG-25, School of Medicine University of

Washington Seattle, WA 98195

Sarah Williams-Blangero

Department of Genetics 
Southwest Foundation for Biomedical Research

P.O. Box 28147

San Antonio, TX 78228

Alexander Wilson

Department of Biometry and Genetics

Louisiana State University Medical Center

1901 Perdido Street

New Orleans, LA 70112

Susan R. Wilson Statistics SMS, IAS Australian National University GPO Box 4 Canberra, ACT 2601 AUSTRALIA

W. H. Wong Department of Statistics The University of Chicago 5734 South University Avenue Chicago, IL 60637

Huixing Yuan

State University of New York, Stony Brook

Stony Brook, NY 11794

JohnJ. Zone

Department of Internal Medicine

University of Utah School of Medicine

420 Chipeta Way

Salt Lake City, UT 84108 